The reactions of starlings to different proportions of models and mimics. Amer. Nat. 94: 271-282.

- J. J. Brower, and P. W. Westcott. 1960. Experimental studies of mimicry. $V$. The reactions of toads (Bufo terrestris) to bumblebees (Bombus americanorum) and their robberfly mimics (Mallophorus bomboides), with a discussion of aggressive mimicry. Amer. Nat. 94: 343-355.

Cerpenter, G. D. H. 1932. Mimicry. Sci. Progr. No. 104: 609-625.

- 1949. Pseudacraca eurytus (L.) (Lep. Nymphalidae) : a study of a polymorphic mimic in various de- grees of speciation. Trans. R. Ent. Soc. London 100: $71-133$.

Fiaker, R. A. 1958. The genetical theory of natural selection. 2d rev. ed. New York: Dover.

Ford, E. B. 1936. The genetics of Papilio dardanus Brown (Lep.). Trans. R. Ent. Soc. London 85: 435466.

Sheppard, P. M. 1958. Natural selection and heredity. London: Hutchinson.

- 1959. The evolution of mimicry; a problem in ecology and genetics. Cold Spring Harbor Symp. Quant. Biol. 24: 131-140.

\title{
A MODEL STREAM FOR STUDIES IN LOTIC ECOLOGY
}

\author{
George H. Laupp' and Kenneth W. CuxMins² \\ Department of Zoology, University of Michigan, Ans Arbor
}

\section{InTRODUCTION}

During the course of an investigation concerning the distribution of stream bottom fauna, a flowing water system was developed which has proven quite valuable for rearing and studying the ecology and behavior of lotic organisms. ${ }^{3}$ In 1914, Shelford conducted some preliminary experiments to delineate responses of animals from riffle and pool communities to various environmental parameters. Since that time, there has been very little experimental work in the laboratory or in field aspects of lotic ecology, in spite of the importance of such procedures in interpreting distributional behavioral patterns. The model stream described in the present paper has enabled the authors to investigate the responses of stream organisms to substrate particle size and food materials under controlled conditions of current velocity, temperature, and light. Results obtained with nymphs of the stone fly Perlesta placida (Hagen) have been used to illustrate the application of the model to one type of investigation in stream ecology. The system is simple, fairly compact, and flexible enough to be of considerable value in teaching and research. In addition to the experiments with stream benthic macroinvertebrates cited above, the model stream has been utilized in studies on the systematics of aquatic insects (Lauff, et al. 1961), fish behavior (Poulson 1960), and life history studies of certain molluscs (Dazo, pers. comm.).

\section{Model Stream}

The model stream (Fig. 1) was composed of 2 fiber glassed plywood troughs, arranged one above the other, and a reservoir $\left(36 \mathrm{ft}^{3}\right.$ ) lined with a plastic film sheet. A centrifugal pump was utilized to raise water from the reservoir through plastic pipes to the upper trough. The volume of water flowing to the troughs was controlled by a gate valve which permitted a part to be cycled directly back to the reservoir. At the upstream end of the upper trough, the water was apportioned between the 2 troughs through a $2 d$ gate valve. The water passed

${ }^{1}$ Present Address : Sapelo Island Research Foundation, Inc., Sapelo Island, Georgia.

Present Address: Department of Biological Sciences, University of Pittsburgh, Pittsburgh 13, Pennsylvania.

This work was sponsored by grant K-12 (C1-C2) from the National Institutes of Health.

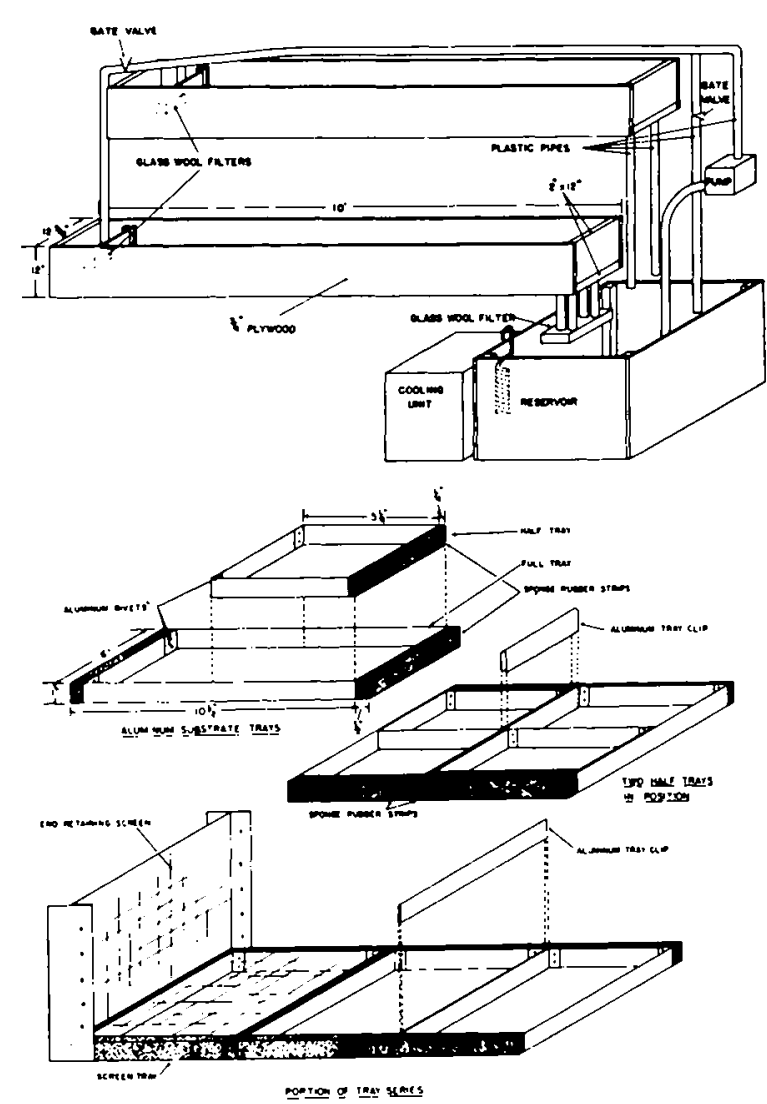

FIG. 1. Model stream and substrate tray system.

into the troughs through glass wool filters and was returned to the reservoir after flowing through standpipes and additional glass wool filters (only one is shown in Fig. 1). Standpipes of various heights allowed the depth of water in the troughs to be varied. It was possible to establish several current regimes by adjusting the pitch of the troughs and the gate valve settings; the current velocities corresponding to various gate valve settings at 
a given pitch were determined with a pigmy current meter (Corbett 1955), though they were also calculated.

The aquarium room used to house this flowing water system was kept essentially at outdoor temperatures the year around. However, during the summer a cooling unit was employed to maintain a water temperature in the range from 19 to $25^{\circ} \mathrm{C}$. With this arrangement, water temperatures simulated those in the field during periods of experimental work.

Various modifications can be made in the model stream to suit particular research needs. For example, the troughs can be constructed in adjustable sections to provide a variable pitch along their length, or lined with disposable plastic film sheets for isotope studies or toxicology experiments such as those conducted by Warren and Douderoff (1957). Refinements for studies concerning the respiration of aquatic invertebrates such as those made by Gaufin and Gaufin (1961) can also be added together with additional temperature and light controls. Sudia (1951) has described a circular system which he employed to investigate the effects of current on mosquito larvae, and Madsen (pers. comm.) is using a small flowing water system for studying distribution patterns of stream organisms.

In small flowing water systems, it may be advisable to utilize a sump pump or paddle wheel device to raise water from reservoir to trough, since circulating pumps have a tendency to warm the water.

\section{SUBSTRATE TRAYS}

A particularly useful experimental arrangement to examine the responses of stream macroinvertebrates to substrate particle size has been employed in the model stream and is diagramed in Figure 1. Individuals of 10 common invertebrate species, collected from Fleming Creek, Washtenaw County, Michigan, were maintained on natural stream substrates at $20^{\circ} \mathrm{C}$ before their utilization in experiments concerning substrate particle size selection. Aluminum trays were designed to fit into the model stream so that sponge rubber stripping glued to either end of the trays insured a tight seal with the sides of the trough. The trays were filled with stream sediments which had been washed, oven dried, and sieved into 8 particle-size categories $(16,8,4,2,1,1 / 2,1 / 4,1 / 8 \mathrm{~mm})$ according to Wentworth classification (Wentworth 1922). Tray-length aluminum clips joined the trays together, and the substrates were smoothed over to minimize barriers between trays. At each end of the series of 8 substrate trays, a tray covered with aluminum screen provided a buffer zone between the substrates and the endretaining screens used to prevent escapement from the experimental area ; animals merely selecting the upstream or downstream end of the enclosure were not in a substrate tray. The screen trays were rimmed with sponge rubber to insure a tight fit against the sides of the trough, the end-retaining screens, and the terminal substrate trays. The system was flexible and convenient since the trays could be arranged in any desired order and were easily removed from the trough for examination.

In addition, aluminum half-trays were constructed to fit inside the full length trays. The use of half-length trays allowed half of each particle size to be altered either by covering it with a skim of silt or by the addition of food substances. In this manner, the importance of silt or food to substrate selection, as determined with full length trays, could be evaluated.

The presence of partitions between substrates did not appear to influence substrate selection, since the animals were observed to move over the substrate surface; the

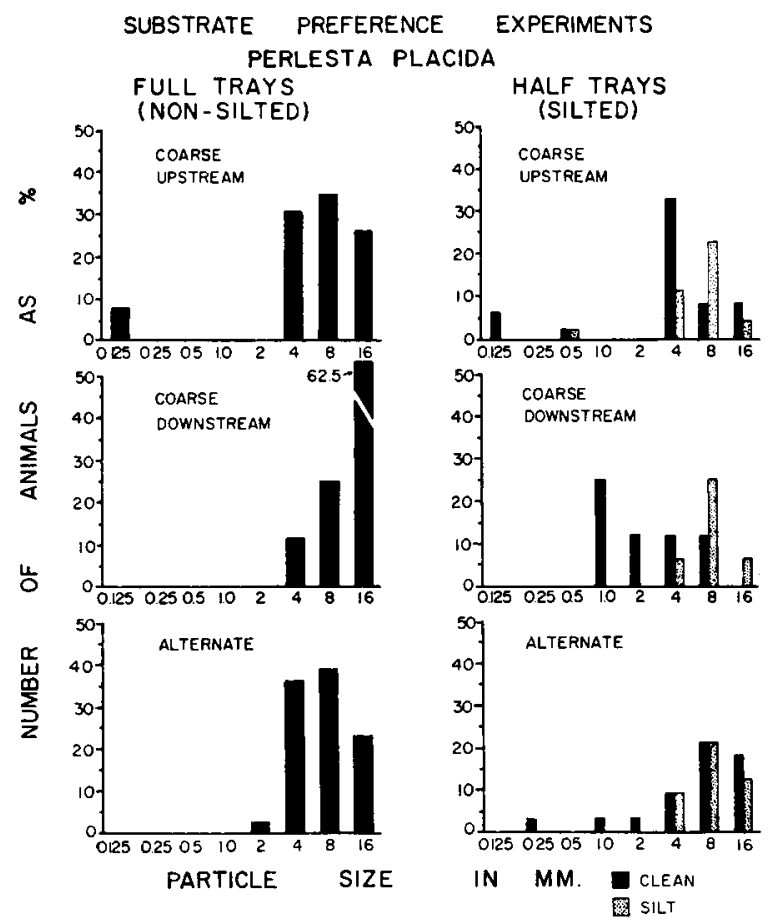

FIG. 2. Substrate preference experiments with the stone fly Perlesta placida (Hagen).

partitions were necessary to maintain particle-size categories in discrete ranges and to reduce the amount of sieving required for replicate experiments.

\section{Experimental Results and Discussion}

Some representative results of stream-tray experiments conducted to determine the role of substrate in stream fauna distribution are given in Figure 2 for nymphs of the stone fly Perlesta placida (Hagen); a more detailed account of the investigations conducted with 10 common species of benthic invertebrates is in preparation. The predaceous nymphs of $P$. placida are quite common in eastern North America, inhabiting the rapid parts of streams and rivers where they are found among coarse substrate materials (Claassen 1931; Frison 1935; Lauff et al. 1961). Nymphs in their later instars were collected from Fleming Creek and kept in aerated containers on natural stream substrates at $20^{\circ} \mathrm{C}$. Two groups of 16 nymphs were alternately introduced into each of 3 arrangements of the substrate trays; these were 2 graded series, one with the largest particle size upstream, the other with the largest size downstream, and one series with the particle sizes alternated. Beginning upstream, the alternate tray arrangement by particle size was $1,8,1 / 4,2,1 / 2$, $16,1 / 8$, and $4 \mathrm{~mm}$. When introduced, each experimental group was divided equally among the 8 substrate trays. The experimental results obtained with the full length trays are presented by tray arrangement (Fig. 2), since the chi-square test for $\mathrm{k}$ independent samples (Siegel 1956) indicated bias due to substrate tray position.

Additional experiments, which will not be discussed here, indicated no significant difference between results of the 24-hr trials and longer term experiments, nor between normal photoperiod experiments and those conducted in complete darkness. Other experiments using reintroduced nymphs demonstrated that the effect of learn- 
ing on substrate tray selection was not significant when tested by the Kolmogorov-Smirnov one-sample test (Siegel 1956).

The nymphs of the stone fly $P$. placida selected the 3 largest particle sizes almost exclusively (significant with the Kolmogorov-Smirnov one-sample test). They showed a tendency to move downstream as evidenced by the recovery of nymphs in the $1 / 8 \mathrm{~mm}$ tray when it was in the terminal downstream position and the reinforced selection of the $16 \mathrm{~mm}$ particle size when it occupied the downstream position. In addition, the largest selection for the $4 \mathrm{~mm}$ particle size occurred when it was at the downstream end. The only selection of the $2 \mathrm{~mm}$ size occurred when it was bordered by fine particle sizes $(1 / 4$ and $1 / 2 \mathrm{~mm}$ ) in the alternate series. The selection of coarse substrates by $P$. placida nymphs agrees well with field observations and particle size determinations.

In order to evaluate the effects of siltation upon the responses of $P$. placida nymphs, the half-tray system was employed. The portions of each particle size enclosed in the half-trays were covered with a skim of silt about $1 \mathrm{~mm}$ thick. This was accomplished with a large bulb pipette when the trays were submerged and in place. The positions of the silted half-trays were alternated along the length of each tray arrangement resulting in a checkerboard pattern. The procedure utilized in the full length, nonsilted substrate tray experiments was followed, except that the total number of nymphs introduced varied from 16 to 64 . An equal number of nymphs was introduced into each half-tray in any given trial.

The predominant selection by $P$. placida nymphs for the 3 largest particle sizes in the coarse upstream and alternate tray arrangements of the silted half-tray experiments is quite similar to that observed in the corresponding nonsilted tray series (Fig. 2). The coarse downstream tray arrangement results showed a selection for the 1 and $2 \mathrm{~mm}$ sediments not previously encountered, since the nymphs were recovered only from the nonsilted halves of these 2 trays. Indeed, all the nymphs recovered from the $2 \mathrm{~mm}$ and finer sediments had selected the nonsilted part. More individuals selected the nonsilted half of the $4 \mathrm{~mm}$ particle size when the trays were arranged in graded series, but the recovery was equal when the $4 \mathrm{~mm}$ tray was in the terminal downstream position of the alternate series. Selection for the silted side of the $8 \mathrm{~mm}$ substrate was greater than (graded series) or equal to (alternate) that for the nonsilted part; the recovery of nymphs in the $16 \mathrm{~mm}$ particle size indicated an essentially equal preference for the silted and nonsilted halves when the results of all 3 tray arrangements are totaled.

In general, silting of the substrates resulted in an increased selection by $P$. placida nymphs for nonsilted fine particle sizes, as compared to the full length (nonsilted) tray results (Fig. 2). Although the silted portion of the $4 \mathrm{~mm}$ substrates was less suitable, silt had little or no effect on the selection of the $16 \mathrm{~mm}$ particles and the silted half of the $8 \mathrm{~mm}$ substrate was actually preferred. Thus, silt in the interstices of the finer sediments appears to be unfavorable for $P$. placida nymphs but makes less difference in coarse substrates where some filling between the particles may be preferable, as indicated by recoveries in the $8 \mathrm{~mm}$ sediments (Fig. 2).

Results from the Perlesta placida experiments exemplify the type of information that can be obtained with the model stream and substrate trays. As pointed out by Cummins (1962), experimental information of this nature, coupled with detailed field data such as that presented by Cummins (1961), Eriksen (1961), and Marzolf
(1962), is needed to delineate the factors which actually determine the distribution of benthic stream organisms.

Thus far, such an experimental approach to the study of benthic distribution has been primarily limited to marine workers (Wieser 1956; Williams 1958; Wilson 1958).

\section{SUMMarY}

The model stream described has wide application in studies of lotic ecology, and the substrate tray system is of particular value in the experimental determination of the factors affecting the microdistribution of benthic organisms. Experiments conducted with nymphs of the stone fly Perlesta placida (Hagen) demonstrated their preference for coarse particle sizes. In addition, silt in the interstices of the finer sediments appears to be unfavorable for the nymphs but makes less difference in the coarse substrates where some filling between the particles may actually be preferable.

\section{ACKNOWLEDGMENTS}

The authors wish to acknowledge gratefully the invaluable assistance of Dr. Clyde H. Eriksen and Dr. G. Richard Marzolf during the course of the present work and in preparation of this paper. We wish to express thanks also to Dr. Frederick E. Smith and Dr. Roger W. Bachmann for advice concerning the statistical treatment of experimental data.

\section{Literature Cited}

Claassen, P. W. 1931. Plecoptera nymphs of America (north of Mexico). Philadelphia: Thomas Say Foundation.

Corbett, D. M. 1955. Stream-gaging procedure. A manual describing methods and practices of the Geological Survey. U. S. Geol. Surv. Water Supply Paper 888: 1-245.

Cummins, K. W. 1961. The micro-distribution of the caddisfly larvae Pycnopsyche lepida (Hagen) and Pycnopsyche guttifer (Walker) in a restricted portion of a small Michigan stream. Unpublished Ph.D. dissertation, Univ. Michigan.

- 1962. An evaluation of some techniques for the collection and analysis of benthic samples with special emphasis on lotic waters. Amer. Midl. Nat. 67: 477504.

Eriksen, C. H. 1961. Respiration and substrate as factors influencing the distribution of the burrowing mayflies Ephemera simulans and Hexagenia limbata. Unpublished Ph.D. dissertation, Univ. Michigan.

Frison, T. H. 1935. The stoneflies, or Plecoptera, of Illinois. Bull. Ill. Nat. Hist. Surv. 20: 281-471.

Gaufin, R. F., and A. R. Gaufin. 1961. The effect of low oxygen concentrations on stoneflies. Proc. Utah Acad. Sci. Arts, Letters 38: 57-64.

Lauff, G. H., K. W. Cummins, and C. H. Eriksen. 1961. The aquatic insects of Fleming Creek. Mimeographed reports.

Marzolf, G. R. 1962. Substrate relations of the burrowing amphipod Pontoporeia affinis Lindstrom. Unpublished Ph.D. dissertation, Univ. Michigan.

Poulson, T. L. 1960. Cave adaptation in amblyopsid fishes. Unpublished Ph.D. dissertation, Univ. Michigan.

Shelford, V. E. 1914. An experimental study of the 
behavior agreement among animals of an animal community. Biol. Bull. 26: 294-315.

Siegel, S. 1956. Nonparametric statistics for the behavioral sciences. New York: McGraw-Hill.

Sudia, W. D. 1951. A device for rearing animals requiring a flowing water environment. Ohio Jour. Sci. 51: 197-202.

Warren, C. E., and P. Douderoff. 1957. Cooperative research at Oregon State College in the biological aspects of water pollution. Trans. First Seminar on Biological Problems in Water Pollution. Cincinnati, Ohio: R. A. Taft Sanitary Engineering Center, April 23-27, 1956: 201-208.
Wentworth, C. K. 1922. A scale of grade and class terms for clastic sediments. Jour. Geol. 30: 377-392.

Wieser, W. 1956. Factors influencing the choice of substratum in Cumella vulgaris Hart (Crustacea, Cumacea). Limnol. Oceanogr. 1: 275-285.

Williams, A. C. 1958. Substrates as a factor in shrimp distribution. Limnol. Oceanogr. 3: 283-290.

Wilson, D. P. 1958. Some problems in larval ecology related to the localized distribution of bottom animals. Pp. 87-103 in: A. A. Buzzati-Traverse (ed.), Perspectives in marine biology. Berkeley and Los Angeles: Univ. Calif. Press.

\title{
A RUNNING RESPONSE OF $A C M A E A$ TO SEASTARS
}

\author{
Abe S. Margolin ${ }^{1}$ \\ Friday Harbor Laboratories, University of Washington
}

\section{INTRODUCTION}

There is a considerable number of reports concerning the reactions of various animals to the presence of seastars. Among the earliest of these are the observations on the swimming behavior of Pecten jacobaeus (Dakin 1910; Bauer 1912), and the reports of the leaping, somersaulting response by snails of the species Nassa mutabilis and $N$. reticulata (Bàuer 1913; Weber 1924; Hoffman 1930). Bullock (1953) studied the reactions of a large number of intertidal gastropods to seastars. Clark (1958), in a study of the reactions of herbivorous gastropods to contact stimuli with carnivorous gastropods, also used some seastars as stimulators. $\mathrm{He}$ reported that escape reactions were displayed by herbivorous gastropods when stimulated by the seastars Coscinasterias calamaria and Astrasole scabra, but not with the common littoral seastar Asterina regulans. Kohn (1961) has summarized these reports in his review of chemoreception in gastropod molluscs, which includes also responses of gastropods to other animals besides seastars. Bullock (1953), testing a number of common species of limpets, snails, and abalone for reactions to a series of common, carnivorous, asteroid species, reported a pattern of reaction which he regarded as an escape response. I was stimulated by Bullock's observations of this striking behavior to conduct a series of tests with the species of Acmaea and the seastars available in the Friday Harbor region of Puget Sound, 2 including 2 limpets and 7 seastars not previously tested.

\section{Materials}

The animals used were collected intertidally or dredged in the San Juan Island (Friday Harbor) region of Puget Sound, Washington. The gastropods were the 5 commonly occurring species of Acmaea: $A$. digitalis, $A$. pelta (=A. cassis), $A$. scutum, $A$. persona, $A$. mitra. The first 3 were used by Bullock (1953) in his experiments.

${ }^{1}$ Present address: Phoenix College, Phoenix, Arizona.

2 This study was made at the Friday Harbor Laboratories of the University of Washington, under an NSF Science Faculty Fellowship.
The seastars were:

$\begin{array}{cc}\text { Order Forcipulata } & \text { Order Phanerozonia } \\ \text { Pisaster ochraceus } & \text { Mediaster aequalis } \\ \text { Pisaster brevispinus } & \text { Dermasterias imbricata } \\ \text { Leptasterias aequalis } & \text { Luidia foliolata } \\ \text { Evasterias troschellii } & \text { Order Spinulosa } \\ \text { Orthasterias koehleri } & \text { Pteraster tasselatum } \\ \text { Pycnopodia helianthoides } & \text { Crossaster papposus } \\ & \text { Henricia leviuscula } \\ & \text { Solaster stimpsoni }\end{array}$

Methons

An attempt was made at first to simulate natural tidepool conditions in the aquarium, using rocks and sand and algae. It proved to be difficult to evaluate accurately the behavior of the limpets in such a situation. It was difficult to make definitely recognizable contact between the seastar and the limpet, or to determine the exact moment of contact. The movements of the limpets were often erratic and not always attributable to stimulation by seastars. It was found that more precise and consistent observations could be obtained by positioning the limpet on the inner side surface of a glass aquarium filled with circulating sea water, allowing sufficient time for the animal to adjust to the situation ( $15 \mathrm{~min}$ ), and then touching it with a seastar so that the tube feet contacted the shellglass junction or the protruding mantle edge. A distinct movement of the limpet away from the seastar was considered a positive reaction. When the limpet failed to move, contact with the seastar was maintained for $3 \mathrm{~min}$; a lack of movement during this entire period was judged a negative reaction. Each individual limpet was stimulated 20 times. The same limpet was not contacted again until it had definitely ceased its movement, and had remained in its position for $10 \mathrm{~min}$. In all instances, 5 individuals of each species were used, making a total of 100 trials for each species of Acmaea with each species of seastar. 